\title{
The Association between Serum Lactate Dehydrogenase Level and In-hospital Death due to Pulmonary Embolism
}

\section{Samad Ghaffari}

Tabriz University of Medical Sciences

\section{Reza Hajizadeh}

Urmia University of Medical Sciences

Tooba Mohammadi

Urmia University of Medical Sciences

Hadis Kavandi

Tabriz University of Medical Sciences

\section{Kamran Mohammadi}

Tabriz University of Medical Sciences

\section{Mehdi Mohebalizadeh}

Urmia University of Medical Sciences

Amin Sedokani ( $\nabla$ a.sedokani@gmail.com )

Urmia University of Medical Sciences

\section{Research Article}

Keywords: Pulmonary Embolism, Lactate dehydrogenase, Mortality

Posted Date: August 18th, 2021

DOI: https://doi.org/10.21203/rs.3.rs-276184/v2

License: (c) (i) This work is licensed under a Creative Commons Attribution 4.0 International License. Read Full License 


\section{Abstract}

Background: Few studies are evaluating the prognostic value of lactate dehydrogenase (LDH) in patients with pulmonary embolism (PE). We analyzed the possible power of serum LDH levels to predict inhospital mortality.

Methods: In this cross-sectional study 217 patients with confirmed PE diagnosis with CT angiography and available serum LDH level at first 24-hours upon admission were included.

Results: The mean age of patients was $63.04 \pm 16.81$ years old, 23 patients $(10.6 \%)$ died during hospitalization. Multivariate analysis showed that only LDH, WBC were independent predictors of inhospital mortality, however, this association was not significant.

Conclusion: LDH can be a good prognostic marker for predicting in-hospital death in patients with pulmonary embolism.

\section{Introduction}

Pulmonary embolism (PE), together with deep vein thrombosis (DVT) termed as venous thromboembolism (VTE), can be a life-threatening condition. So, accurate and immediate diagnosis is critical. [1] Validated Wells [2] and revised Geneva rules [3], which categorize patients according to the pretest probability of PE are frequently used as clinical tools to help diagnosis of PE. In a non-high risk patient based on one of these criteria, D-dimer level below $500 \mu \mathrm{g} / \mathrm{L}$ can rule out the PE diagnosis with high confidence in about $20-30 \%$ of patients without the need for additional imaging. [4]

On the other hand, because of limited number of intensive care unit (ICU) beds in many health centers and because of high cost of ICU admissions, finding high risk patients and risk stratification of patients are very important. Although there are some scoring systems such as pulmonary embolism severity index (PESI) to define high risk PE patients, still we need more investigations to find biomarkers which have association with higher mortality to extend our knowledge about pathophysiology of disease.

LDH is an enzyme found in almost all cells of body. It has five different subtypes with different distribution in tissues and releases in the bloodstream with cell and/or tissue injuries. [5].

According to previous studies, significant association has been reported between serum LDH level and pump thrombosis in patients who have left ventricular assist device (LVAD). [6, 7] LDH-1 isoenzyme especially showed high relation to pump thrombosis.[8] Significant correlation between elevated LDH level and some other thrombotic events has been demonstrated. In a study about predictors of splanchnic vein thrombosis, LDH $<500 \mathrm{U} / \mathrm{L}$ was found to be associated with thrombosis. [9] In another study, an association was seen between elevated LDH level -as a marker of hemolysis- and thrombosis risk in paroxysmal nocturnal hemoglobinuria patients. $[10,11]$ Because LDH has association with tissue 
damage and is involved in anaerobic metabolism of glucose in decreased oxygen supply, theoretically its increased levels could predict adverse outcome in patients with severe pulmonary thromboembolism. [12]

Elevated serum LDH also was identified as an independent risk factor for venous thromboembolism in patients with testicular germ cell tumor undergoing chemotherapy. [11]

Higher serum LDH level has been reported in PE patients.[13] Based on another study, no association was found between LDH level and bleeding or thrombosis, but higher LDH level on ICU admission was shown to be significantly associated with increased 7-day and 30-day mortality. [14]

Importance of LDH as a marker of severity in PE has been stated in some studies [15], while others has been reported no significant association between PE and LDH level. [16] Finding new biomarkers can help us to achieve better risk stratification and treatment strategies in order to reduce mortality of PE patients.

In current study, we aimed to find out the possible association of serum LDH level and in hospital mortality of PE patients.

\section{Methods}

In this cross-sectional study 217 patients admitted between 2018 till 2020 in two tertiary hospitals with acute PE were included. Our inclusion criteria included as hospitalized patients aged over 18 years, confirmed PE diagnosis with CT angiography and available serum LDH level at first 24-hours upon admission.

Our exclusion criteria were hepatic and renal diseases, pregnancy, hemolytic disorders, left ventricular infarction, recent stroke, positive history of active cancer, acute and chronic infections and reticuloendothelial- related diseases were excluded. Segmental and sub-segmental PE was treated with anticoagulant while massive PE defined as PE with systolic blood pressure less than 90 or/and existence of thrombus in left or right or main pulmonary artery took thrombolytic therapy. [17] Pulmonary computed tomography (CT) angiogram films were reported by two expert radiologists.

Diagnosis of PE was made by CTPA (Siemens 32-slice computed tomography scanners). Two expert radiologists were investigated CTPA images as blinded fashion.

This study was approved by ethics committee of our University. All patients had signed informed consent form and patient anonymity was preserved in our study.

Any death during hospital course due to PE was defined as in-hospital mortality. When death occurred due to non-PE causes (e.g. myocardial infarction, intracranial or gastrointestinal bleeding), patients were excluded from study. Overlay one patient had intracranial bleeding after fibrinolytic therapy and was excluded. 
We measured simplified Pulmonary Embolism Severity Index (sPESI) value for all the patients. Factors including age over 80 years, positive history of cancer, heart rate below 110 beats/minute, chronic cardiopulmonary disease, systolic blood pressure less than $100 \mathrm{~mm} \mathrm{Hg}$, and oxyhemoglobin saturation less than $90 \%$ were assessed in this scoring system and each variable has one point. The patient will categorized as high risk even with presence of one point. [18]

Information about demographic characteristics of the patients, past medical history as well as presenting vital sings, laboratory variables and oxygen saturation, were collected from their medical records.

Hypertension was defined as SBP $\geq 140 \mathrm{mmHg}$ or DBP $\geq 90 \mathrm{mmHg}$.[19] Diabetes mellitus was defined as fasting plasma glucose levels of $\geq 126 \mathrm{mg} / \mathrm{dl}$ and $\mathrm{HbA} 1 \mathrm{c} \geq 6.5 \%$. [20]

Simplified pulmonary embolism severity index was calculated according to previous studies. [18]

Right ventricular dysfunction was defined as the presence of right ventricular dilatation and a TAPSE less than $16 \mathrm{~mm}$ in echocardiography findings. [21] Every ECG was reported by two expert cardiologists to find out right ventricular strain pattern (inverted T wave in V1-V3).

\section{Statistical analysis}

IBM SPSS V.22 software was used for statistical analysis (IBM Corp., Armonk, NY, USA). We used t-test for quantitative values and chi-squire test for qualitative variables. Multiple linear regression and ROC (receiver operating characteristics) curve were used to find cutoff value for LDH level and mortality. Univariate and multivariate analyses were employed to analyze risk factors for mortality

\section{Results}

In this cross-sectional study, we included 217 patients with definite diagnosis of pulmonary embolism. The mean age of patients was $63.04 \pm 16.81$ years, 98 patients $(45.2 \%)$ were female. During hospital admission 23 patients (10.6\%) died. Past medical history showed that 40 patients (18.4\%) had diabetes mellitus, 78 patients $(35.9 \%)$ had hypertension, 31 patients (14.3\%) had history of smoking. Pulmonary embolism was confirmed in all cases by computed tomography (CT) angiography. Table 1 shows demographic, laboratory and physical exam findings in patients with pulmonary embolism according to their in-hospital mortality. Table 2 shows association between LDH and other variables. 
Table 1

the association between demographic, laboratory and physical exam findings and hospital death.

\begin{tabular}{|c|c|c|c|}
\hline \multirow[t]{3}{*}{ Variable } & \multicolumn{2}{|l|}{ Hospital death } & \multirow[t]{3}{*}{ p-value } \\
\hline & Yes & NO & \\
\hline & $23(10.6)$ & 194(89.4) & \\
\hline Age & $64.04 \pm 18.18$ & $62.93 \pm 16.69$ & 0.763 \\
\hline Gender(female) & $13(56.5 \%)$ & $85(43.8 \%)$ & 0.247 \\
\hline Hypertension & $9(39.1 \%)$ & $69(35.6 \%)$ & 0.895 \\
\hline Diabetes mellitus & $6(26.1 \%)$ & $34(17.5 \%)$ & 0.391 \\
\hline \multicolumn{4}{|l|}{ Laboratory variables } \\
\hline Lactate dehydrogenase (LDH) & $873.65 \pm 514.15$ & $609.15 \pm 343.57$ & 0.024 \\
\hline White blood cells $\left(\times 10^{3}\right)$ & $13.69 \pm 44.46$ & $10.51 \pm 15.07$ & 0.003 \\
\hline Hemoglobin & $23.74 \pm 2.77$ & $12.96 \pm 2.15$ & 0.647 \\
\hline Mean corpuscular volume & $80.48 \pm 5.43$ & $81.29 \pm 5.43$ & 0.496 \\
\hline Platelets $\left(\times 10^{3}\right)$ & $213.22 \pm 86.50$ & $206.07 \pm 72.91$ & 0.664 \\
\hline Red cell distribution width (RDW) & $16.40 \pm 2.32$ & $15.07 \pm 2.58$ & 0.019 \\
\hline Total cholesterol & $160.13 \pm 37.19$ & $167.16 \pm 42.45$ & 0.449 \\
\hline Triglyceride & $141.74 \pm 67.86$ & $142.43 \pm 97.78$ & 0.974 \\
\hline \multicolumn{4}{|l|}{ Physical exam and ECG findings } \\
\hline Heart rate & $104.83 \pm 17.01$ & $96.35 \pm 19.54$ & 0.048 \\
\hline Systolic blood pressure & $101.22 \pm 18.77$ & $121.53 \pm 21.14$ & $<0.001$ \\
\hline Diastolic blood pressure & $63.91 \pm 12.77$ & $74.72 \pm 12.06$ & $<0.001$ \\
\hline O2 saturation & $81.30 \pm 7.92$ & $87.62 \pm 9.15$ & 0.001 \\
\hline $\mathrm{T}$ inversion in $\mathrm{V} 1-\mathrm{V} 3$ & $8(34.8 \%)$ & $71(36.6 \%)$ & 0.846 \\
\hline \multicolumn{4}{|l|}{ Echocardiography findings } \\
\hline Tricuspid regurgitation gradient & $39.65 \pm 16.13$ & $34.73 \pm 20.32$ & 0.264 \\
\hline Right ventricular enlargement & $19(82.6 \%)$ & $122(62.9 \%)$ & 0.067 \\
\hline Right ventricular dysfunction & 19(82.6\%) & $114(58.8 \%)$ & 0.040 \\
\hline
\end{tabular}




\begin{tabular}{|llll|}
\hline Variable & \multicolumn{2}{l}{ Hospital death } & p-value \\
\cline { 2 - 3 } & Yes & No & \\
& $23(10.6)$ & $194(89.4)$ & \\
\hline Massive Emboli & $2(8.7 \%)$ & $4(2.1 \%)$ & $<0.001$ \\
\hline Simplified PESI score $\geq 1$ & $23(100.0 \%)$ & $124(63.9 \%)$ & $<0.0001$ \\
\hline
\end{tabular}

Table 2

univariate and multivariate analysis of risk factors of in-hospital mortality

\begin{tabular}{|c|c|c|c|c|c|c|}
\hline \multirow[t]{2}{*}{ Variable } & \multicolumn{3}{|l|}{ Univariate } & \multicolumn{3}{|l|}{ multivariate } \\
\hline & $\begin{array}{l}\text { Unadjusted } \\
\text { OR }\end{array}$ & $95 \% \mathrm{Cl}$ & $\begin{array}{l}\mathrm{P}- \\
\text { value }\end{array}$ & $\begin{array}{l}\text { Unadjusted } \\
\text { OR }\end{array}$ & $95 \% \mathrm{Cl}$ & $\begin{array}{l}\mathrm{P}- \\
\text { value }\end{array}$ \\
\hline $\mathrm{O}_{2}$ saturation & 0.932 & $\begin{array}{l}0.893- \\
0.974\end{array}$ & 0.002 & 0.996 & $\begin{array}{l}0.930- \\
1.067\end{array}$ & 0.907 \\
\hline Heart rate & 1.022 & $\begin{array}{l}1.000- \\
1.045\end{array}$ & 0.051 & & & \\
\hline $\begin{array}{l}\text { Systolic blood } \\
\text { pressure }\end{array}$ & 0.949 & $\begin{array}{l}0.924- \\
0.974\end{array}$ & $<.001$ & 0.968 & $\begin{array}{l}0.929- \\
1.009\end{array}$ & 0.126 \\
\hline $\begin{array}{l}\text { Diastolic blood } \\
\text { pressure }\end{array}$ & 0.934 & $\begin{array}{l}0.900 \\
-0.968\end{array}$ & <. 001 & 0.991 & $\begin{array}{l}0.930- \\
1.057\end{array}$ & 0.794 \\
\hline WBC & 1.00 & $1.00-1.00$ & $\hat{0}_{0.001}$ & 1.000 & $\begin{array}{l}1.000- \\
1.000\end{array}$ & 0.052 \\
\hline $\mathrm{Cr}$ & 2.077 & $\begin{array}{l}1.047- \\
4.119\end{array}$ & 0.036 & 1.091 & $\begin{array}{l}0.389- \\
3.064\end{array}$ & 0.868 \\
\hline RDW & 1.189 & $\begin{array}{l}1.026- \\
1.378\end{array}$ & 0.022 & 1.141 & $\begin{array}{l}0.925- \\
1.408\end{array}$ & 0.217 \\
\hline LDH & 1.001 & $\begin{array}{l}1.000- \\
1.002\end{array}$ & 0.005 & 1.001 & $\begin{array}{l}1.000- \\
1.003\end{array}$ & 0.082 \\
\hline RV strain & 1.082 & $\begin{array}{l}0.437- \\
2.679\end{array}$ & 0.864 & & & \\
\hline RV dysfunction & 0.300 & $\begin{array}{l}0.098- \\
0.915\end{array}$ & 0.034 & 2.327 & $\begin{array}{l}0.668- \\
8.103\end{array}$ & 0.185 \\
\hline Massive Emboli & 0.168 & $\begin{array}{l}0.055- \\
0.511\end{array}$ & 0.002 & 0.165 & $\begin{array}{l}0.042- \\
0.651\end{array}$ & 0.010 \\
\hline sPESI & 3.047 & $\begin{array}{l}1.912- \\
4.857\end{array}$ & <. 001 & 2.304 & $\begin{array}{l}1.245- \\
4.266\end{array}$ & 0.008 \\
\hline
\end{tabular}


Univariate analysis showed that among laboratory data findings, higher levels of LDH, white blood cells (WBC), red distribution width (RDW) had significant association with in-hospital mortality. (P values < 0.05). (Table 2) only LDH, WBC were independent predictors of in-hospital mortality, however this association was not significant statistically (Table 2). ROC curve showed that an LDH cut-off value of $515 \mathrm{U} / \mathrm{l}$ had a sensitivity of $91.3 \%$ and specificity of $45.9 \%$ in predicting in-hospital mortality ( $95 \%$ confidence interval $=0.636-0.761, p=0.0003)($ Fig. 1$)$.

Table 3 shows the association between LDH and other variables.

Table 3

Correlation between different variables and LDH.

\begin{tabular}{|c|c|c|c|c|c|c|}
\hline Source & variables & $\begin{array}{l}\text { Type III Sum of } \\
\text { Squares }\end{array}$ & df & Mean Square & $\mathbf{F}$ & Sig. \\
\hline \multirow[t]{10}{*}{ LDH } & Right ventricular strain & 42.406 & 179 & .237 & 1.119 & .353 \\
\hline & 02 saturation & 13241.039 & 179 & 73.972 & 1.054 & .441 \\
\hline & White blood cell & 2568640821.813 & 179 & 14349948.725 & 1.185 & .276 \\
\hline & RDW & 1083.184 & 179 & 6.051 & 620 & .978 \\
\hline & Heart rate & 72241.562 & 179 & 403.584 & 1.608 & .044 \\
\hline & $\begin{array}{l}\text { Systolic blood } \\
\text { pressure }\end{array}$ & 87679.514 & 179 & 489.830 & 1.224 & .237 \\
\hline & $\begin{array}{l}\text { Diastolic blood } \\
\text { pressure }\end{array}$ & 29181.577 & 179 & 163.026 & 1.234 & .228 \\
\hline & RV dysfunction & 45.151 & 179 & .252 & 1.474 & .082 \\
\hline & Massive Emboli & 46.194 & 179 & .258 & 1.194 & .267 \\
\hline & Simplified PESI & 210.916 & 179 & 1.178 & 1.108 & .367 \\
\hline
\end{tabular}

\section{Discussion}

In this cross-sectional study, we evaluated the level of lactate dehydrogenase in 217 patients with a definite diagnosis of pulmonary embolism. Our study showed that serum LDH was associated with higher risk of in-hospital death, but this association was not significant in multivariate analysis. By studying new biomarkers affecting outcome of patients and better understanding of pathophysiology of disease, early and more effective treatment with lesser cost could be achieved. 
Increased LDH has been linked to higher risk of ARDS [22], in ICU complications [23], and death. [22, 24]

Pulmonary thromboembolism is one of the most dangerous complications involving cardiovascular system. [25] The importance of evaluating and predicting the course and outcome of the disease has been an era of interest for researchers. There are a few studies investigating the association between LDH level in PE patients and in-hospital mortality.

In line with our study, Leite et al in a retrospective study included 165 patients with acute PE. The main end point of this study were in-hospital and all-cause mortality. They showed that LDH had significant association with in-hospital and late all-cause mortality and LDH cut-off value of $310 \mathrm{U} / \mathrm{I}$ with a sensitivity of $54.5 \%$ and specificity of $71.3 \%$ could predict adverse outcome. [26] Our study by a larger sample size, showed that a LDH cut-off value of $515 \mathrm{U} / \mathrm{I}$ had a sensitivity of $91.3 \%$ and specificity of $45.9 \%$ in predicting in-hospital mortality.

Serum LDH level has been reported to be higher in massive PTE compared to sub-massive and nonmassive PTE. $[27,28]$ The increased LDH level was associated with higher pulmonary artery pressure, right ventricular dysfunction. [27]

Lactate dehydrogenase is abundantly made in the human body.lt has 5 types of isozymes, LDH-1 and LDH-3 isozymes are presented in cardiomyocytes and pneumocytes respectively. [29,30] Karlsson et al showed that LDH had significant correlation with hypoxic ischemic encephalopathy in newborn infants. [31] By catalyzing pyruvate to lactate, LDH is an important enzyme in anaerobic metabolism of glucose during hypoxia. [12]

A recent study showed that patients with COVID-19 and high LDH levels are more susceptible to develop acute respiratory distress syndrome. [32] Increasing in cardiac, lung and hypoxic tissue damage makes LDH a suitable biomarker for predicting outcome of patients with pulmonary embolism. Ben et al suggested that using LDH-3 and D-dimer together could improve the diagnosis of PE. [33] Our study showed that presence of massive embolism and higher SPESI were better predictors of in-hospital death, but higher LDH and WBC also could help in better differentiation of patients. Further studies by revealing pathophysiology of underlying causes of LDH related morbidity and mortality could improve patients' management and outcome.

\section{Limitations of study}

We didn't have autopsy for all deaths and pure PE related death could be misdiagnosed in few cases. Although we used our exclusion criteria to decrease the effect of confounding factors, still other factors such as undiagnosed cancers and some medications could affect our results adversely.

\section{Abbreviations}

LDH: lactate dehydrogenase 
PE: pulmonary embolism

VTE: venous thromboembolism

CTPA: Computed tomography pulmonary angiography

LVAD: left ventricular assist device

ICU: Intensive care unite

\section{Declarations}

\section{Ethics approval and consent to participate}

This study was approved by ethics committee of Urmia University of Medical Sciences and were performed in accordance with the principles of the Declaration of Helsinki, and the International Conference on Harmonization notes for guidance on Good Clinical Practice (ICH/CPMP/135/95). All patients provided written informed consent prior to any study-related procedure. The approved ethical code for this study is IR.UMSU.REC.1399.143.

\section{Consent for publication}

Not applicable.

\section{Availability of data and materials}

The data that support the findings of this study are available from the corresponding author, A.S , upon reasonable request.

\section{Competing interests}

The authors declare that they have no conflict of interest.

\section{Funding}

The authors declare no funding for this study.

\section{Authors' contributions}


The study was designed by S.G. and R.H., data collection and manuscript written by T.M., K.M., M.M., S.G., H.K., and A.S. interpreted the data, and R.H. and A.S. revised the manuscript for important intellectual content. All authors read and approved the final manuscript

\section{Acknowledgements}

Pulmonary embolism registry of Tabriz University of Medical Sciences (Cardiovascular Research Center) supports data availability for this study.

\section{References}

1. Stals MA, Klok FA, Huisman MV: Diagnostic management of acute pulmonary embolism in special populations. Expert Review of Respiratory Medicine 2020:1-8.

2. Wells PS, Anderson DR, Rodger M, Ginsberg JS, Kearon C, Gent M, Turpie AG, Bormanis J, Weitz J, Chamberlain M: Derivation of a simple clinical model to categorize patients probability of pulmonary embolism: increasing the models utility with the SimpliRED D-dimer. Thrombosis and haemostasis 2000, 83(03):416-420.

3. Le Gal G, Righini M, Roy P-M, Sanchez O, Aujesky D, Bounameaux H, Perrier A: Prediction of pulmonary embolism in the emergency department: the revised Geneva score. Annals of internal medicine 2006, 144(3):165-171.

4. Lucassen W, Geersing G-J, Erkens PM, Reitsma JB, Moons KG, Büller H, van Weert HC: Clinical decision rules for excluding pulmonary embolism: a meta-analysis. Annals of internal medicine 2011, 155(7):448-460.

5. Holmes RS, Goldberg E: Computational analyses of mammalian lactate dehydrogenases: human, mouse, opossum and platypus LDHs. Computational biology and chemistry 2009, 33(5):379-385.

6. Grabska J, Schlöglhofer T, Gross C, Maw M, Dimitrov K, Wiedemann D, Zimpfer D, Schima H, Moscato $\mathrm{F}$ : Early detection of pump thrombosis in patients with left ventricular assist device. ASAIO Journal: Artificial Organ Research and Development 2020, 66(4):348-354.

7. Thenappan T, Stulak JM, Agarwal R, Maltais S, Shah P, Eckman P, Emani S, Katz JN, Gregoric I, Keebler ME: Early intervention for lactate dehydrogenase elevation improves clinical outcomes in patients with the HeartMate II left ventricular assist device: Insights from the PREVENT study. The Journal of Heart and Lung Transplantation 2018, 37(1):25-32.

8. Topkara V, Garan A, Yuzefpolskaya M, Takeda K, Takayama H, Cagliostro B, Effner L, Castagna F, Singh S, Fried J: Lactate dehydrogenase isoenzyme monitoring in patients with continuous-flow left ventricular assist devices (CF-LVADs). The Journal of Heart and Lung Transplantation 2016, 35(4):S393.

9. Toqué L, Hamy A, Hamel JF, Cesbron E, Hulo P, Robert S, Aube C, Lermite E, Venara A: Predictive factors of splanchnic vein thrombosis in acute pancreatitis: A 6-year single-center experience. 
Journal of Digestive Diseases 2015, 16(12):734-740.

10. Lee JW, Jang JH, Kim JS, Yoon S-S, Lee J-H, Kim Y-K, Jo D-Y, Chung J, Sohn SK: Clinical signs and symptoms associated with increased risk for thrombosis in patients with paroxysmal nocturnal hemoglobinuria from a Korean Registry. International journal of hematology 2013, 97(6):749-757.

11. Paffenholz P, Grein K, Heidegger I, Nestler T, Grabbert M, Salem J, Hellmich M, Pfister D, Heidenreich A: Predictors of thrombosis in testicular cancer during platinum-based chemotherapy. World Journal of Urology 2019, 37(9):1907-1916.

12. Adeva-Andany M, López-Ojén $M$, Funcasta-Calderón R, Ameneiros-Rodríguez E, Donapetry-García $C$, Vila-Altesor M, Rodríguez-Seijas J: Comprehensive review on lactate metabolism in human health. Mitochondrion 2014, 17:76-100.

13. Atikcan Ş, Atalay F, Turgut D, Ünsal E: Pulmonary thromboembolism: A retrospective evaluation of 42 cases. Solunum Hastaliklari 2002, 13:87-93.

14. Russell L, Madsen M, Dahl M, Kampmann P, Perner A: Prediction of bleeding and thrombosis by standard biochemical coagulation variables in haematological intensive care patients. Acta Anaesthesiologica Scandinavica 2018, 62(2):196-206.

15. Babaoglu E, Hasanoglu HC, Senturk A, Karalezli A, Kilic H, Aykun G, Oztuna D: Importance of biomarkers in risk stratification of pulmonary thromboembolism patients. Journal of investigative medicine: the official publication of the American Federation for Clinical Research 2014, 62(2):328331.

16. Gülşen Z, Koşar PN, Gökharman FD: Comparison of multidetector computed tomography findings with clinical and laboratory data in pulmonary thromboembolism. Polish journal of radiology 2015, 80:252.

17. Hajizadeh R, Ghaffari S, Rajebi H, Kavandi H, Javanshir E, Fahimi G, Ghodratizadeh S: Short-term mortality of patients with saddle pulmonary embolism: A single-center study. Turk Kardiyoloji Dernegi arsivi: Turk Kardiyoloji Derneginin yayin organidir 2019, 47(4):273-280.

18. Ostovan MA, Ghaffari S, Pourafkari L, Dehghani P, Hajizadeh R, Nadiri M, Ghaffari MR: Modification of simplified pulmonary embolism severity index and its prognostic value in patients with acute pulmonary embolism. Heart, Lung and Circulation 2016, 25(2):184-190.

19. Members ATF, Mancia G, Fagard R, Narkiewicz K, Redon J, Zanchetti A, Böhm M, Christiaens T, Cifkova R, De Backer $\mathrm{G}$ et al: 2013 ESH/ESC Guidelines for the management of arterial hypertension: The Task Force for the management of arterial hypertension of the European Society of Hypertension (ESH) and of the European Society of Cardiology (ESC). European Heart Journal 2013, 34(28):2159-2219.

20. Use of Glycated Haemoglobin (HbA1c) in the Diagnosis of Diabetes Mellitus: Abbreviated Report of a WHO Consultation. Geneva: (c) World Health Organization 2011.; 2011.

21. Naksuk N, Tan N, Padmanabhan D, Kancharla K, Makkar N, Yogeswaran V, Gaba P, Kaginele P, Riley DC, Sugrue AM et al: Right Ventricular Dysfunction and Long-Term Risk of Sudden Cardiac Death in 
Patients With and Without Severe Left Ventricular Dysfunction. Circulation: Arrhythmia and Electrophysiology 2018, 11(6):e006091.

22. Wu C, Chen X, Cai Y, Zhou X, Xu S, Huang H, Zhang L, Zhou X, Du C, Zhang Y: Risk factors associated with acute respiratory distress syndrome and death in patients with coronavirus disease 2019 pneumonia in Wuhan, China. JAMA internal medicine 2020.

23. Fan BE, Chong VCL, Chan SSW, Lim GH, Lim KGE, Tan GB, Mucheli SS, Kuperan P, Ong KH: Hematologic parameters in patients with COVID-19 infection. American journal of hematology 2020, 95(6):E131-E134.

24. Zhou F, Yu T, Du R, Fan G, Liu Y, Liu Z, Xiang J, Wang Y, Song B, Gu X: Clinical course and risk factors for mortality of adult inpatients with COVID-19 in Wuhan, China: a retrospective cohort study. The lancet 2020.

25. Sakr Y, Giovini M, Leone M, Pizzilli G, Kortgen A, Bauer M, Tonetti T, Duclos G, Zieleskiewicz L, Buschbeck S: The clinical spectrum of pulmonary thromboembolism in patients with coronavirus disease-2019 (COVID-19) pneumonia: A European case series. Journal of critical care 2020, 61:3944.

26. Leite L, Moura J, Ferreira R, Lazaro S, Madaleno J, Moreira N, Baptista R, Silva N, Elvas L, Pego M: LDH as a predictor of in-hospital and late mortality in acute pulmonary embolism. European heart journal 2013, 34(suppl_1).

27. Zhang $Y$, Yang $Y-H$, Pang B-S, Wang $\mathrm{C}$ : The changes of serum enzymes and cardiac troponin I in patients with acute pulmonary thromboembolism. Zhonghua jie he he hu xi za zhi= Zhonghua jiehe he huxi zazhi = Chinese journal of tuberculosis and respiratory diseases 2007, 30(9):667-672.

28. Ben S-q, Ni S-s, Shen H-h, Shi Y-x, Huang S-b, Xu J-h, Huang J-f: The dynamic changes of LDH isoenzyme 3 and D-dimer following pulmonary thromboembolism in canine. Thrombosis research 2007, 120(4):575-583.

29. Martinez-Outschoorn UE, Prisco M, Ertel A, Tsirigos A, Lin Z, Pavlides S, Wang C, Flomenberg N, Knudsen ES, Howell A et al: Ketones and lactate increase cancer cell "stemness," driving recurrence, metastasis and poor clinical outcome in breast cancer: achieving personalized medicine via Metabolo-Genomics. Cell cycle (Georgetown, Tex) 2011, 10(8):1271-1286.

30. Henry BM, Aggarwal G, Wong J, Benoit S, Vikse J, Plebani M, Lippi G: Lactate dehydrogenase levels predict coronavirus disease 2019 (COVID-19) severity and mortality: A pooled analysis. Am J Emerg Med 2020, 38(9):1722-1726.

31. Karlsson M, Wiberg-Itzel E, Chakkarapani E, Blennow M, Winbladh B, Thoresen M: Lactate dehydrogenase predicts hypoxic ischaemic encephalopathy in newborn infants: a preliminary study. Acta paediatrica (Oslo, Norway: 1992) 2010, 99(8):1139-1144.

32. Zhou Y, Ding N, Yang G, Peng W, Tang F, Guo C, Chai X: Serum lactate dehydrogenase level may predict acute respiratory distress syndrome of patients with fever infected by SARS-CoV-2. Ann Transl Med 2020, 8(17):1118-1118. 
33. Ben SQ, Ni SS, Shen HH, Shi YX, Huang SB, Xu JH, Huang JF: The dynamic changes of LDH isoenzyme 3 and D-dimer following pulmonary thromboembolism in canine. Thromb Res 2007, 120(4):575-583.

\section{Figures}

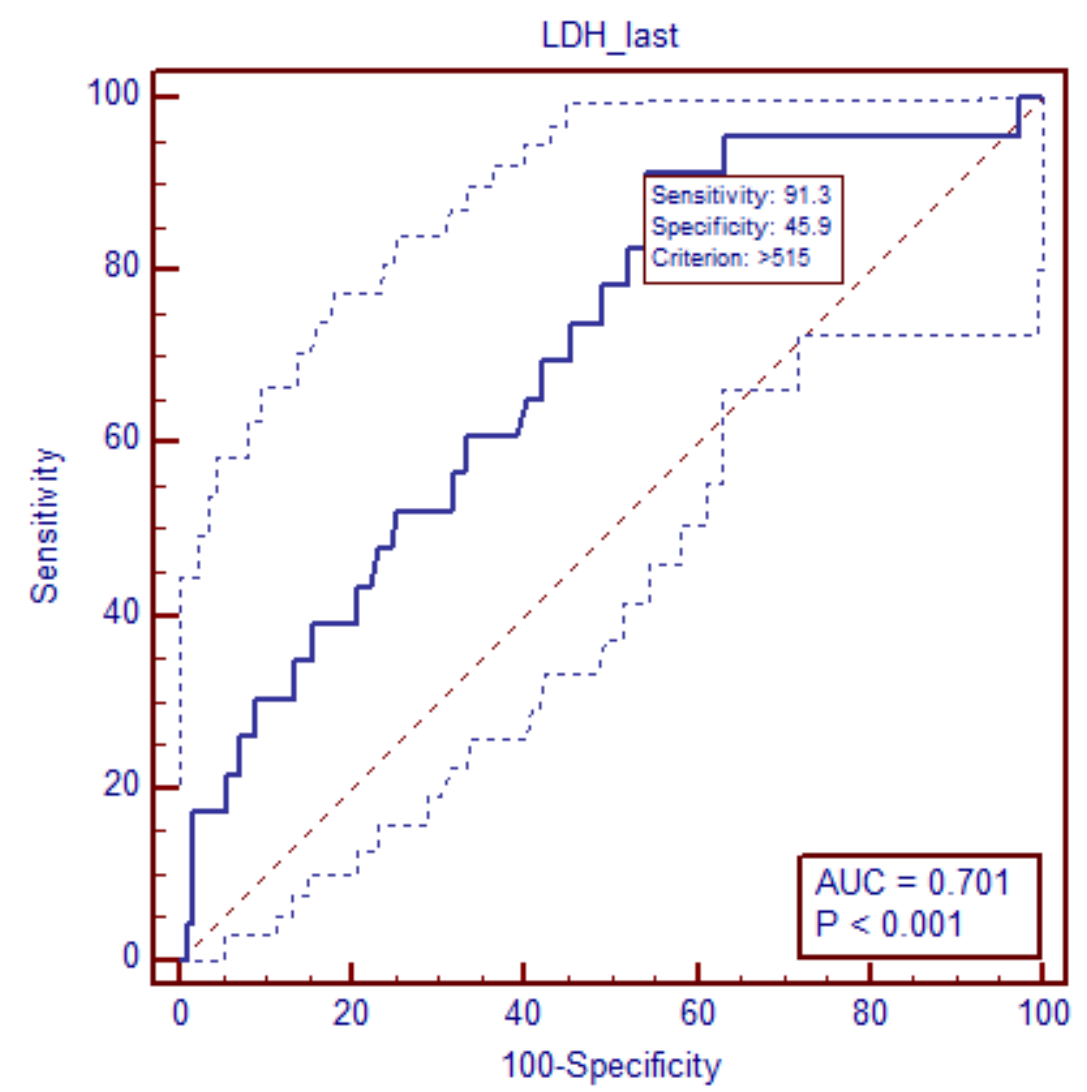

\section{Figure 1}

A ROC curve (receiver operating characteristic curve) shows the best cut off point for LDH to predict hospital death. 